\title{
Mechanical and structural properties of radiation-damaged allanite-(Ce) and the effects of thermal annealing
}

Claudia E. Reissner ${ }^{1, *}$, Ulrich Bismayer ${ }^{2}$, Daniel Kern³, Michael Reissner ${ }^{3}$, Sulgiye Park ${ }^{4}$, Jiaming Zhang ${ }^{4}$, Rodney C. Ewing ${ }^{4}$, Anna Shelyug ${ }^{5}$, Alexandra Navrotsky ${ }^{5}$, Carsten Paulmannn ${ }^{2,6}$, Radek Škoda ${ }^{7}$, Lee A. Groat ${ }^{8}$, Herbert Pöllmann ${ }^{1}$ and Tobias Beirau ${ }^{1, *}$

${ }^{1}$ Institute of Geosciences and Geography, Martin-Luther-University Halle-Wittenberg, 06120 Halle (Saale), Germany

${ }^{2}$ Department of Earth Sciences, University of Hamburg, 20146 Hamburg, Germany

${ }^{3}$ Institute of Solid State Physics, TU Wien, 1040 Vienna, Austria

${ }^{4}$ Department of Geological Sciences, Stanford University, Stanford, CA 94305-2115, U.S.A.

${ }^{5}$ Peter A. Rock Thermochemistry Laboratory \& NEAT ORU, University of California Davis, Davis, CA 95616, U.S.A.

${ }^{6}$ HASYLAB, DESY, 22603 Hamburg, Germany

${ }^{7}$ Institute of Geological Sciences, Faculty of Science, Masaryk University, 61137 Brno, Czech Republic

${ }^{8}$ Department of Earth, Ocean and Atmospheric Sciences, University of British Columbia, Vancouver,

BC V6T 1Z4, Canada

*Corresponding authors: claudia.reissner@geo.uni-halle.de, +49/345/5528247; and tobias.beirau@geo.unihalle.de, $+49 / 345 / 5526123$

\section{Abstract}

The onset of thermally induced, heterogeneous structural reorganization of highly radiation-damaged allanite-(Ce) begins at temperatures below $700 \mathrm{~K}$. Three strongly disordered allanite samples (S74 20414: $0.55 \mathrm{wt} \% \mathrm{ThO}_{2}$, $22.1 \mathrm{wt} \%$ REE oxides, and maximum radiation dose $3.5 \times 10^{18} \alpha$-decay/g; LB-1: $1.18 \mathrm{wt} \% \mathrm{ThO}_{2}, 19.4 \mathrm{wt} \% \mathrm{REE}$ oxides, and maximum radiation dose $2.0 \times 10^{19} \alpha$-decay/g; R1: $\sim 1.6 \mathrm{wt} \% \mathrm{ThO}_{2}, 19.7 \mathrm{wt} \%$ REE oxides, and maximum radiation dose $2.6 \times 10^{18} \alpha$-decay/g) were step-wise annealed to $1000 \mathrm{~K}$ in air. Using orientationdependent nanoindentation, synchrotron single-crystal X-ray diffraction (synchrotron XRD), X-ray powder diffraction (powder XRD), differential scanning calorimetry and thermogravimetric analysis (DSC/TG), mass spectrometry (MS), ${ }^{57} \mathrm{Fe}$ Mössbauer spectroscopy and high-resolution transmission electron microscopy (HRTEM), a comprehensive understanding of the structural processes involved in the annealing was obtained. As a result of the overall increasing structural order, a general increase of hardness (pristine samples: 8.2-9.3 GPa, after annealing at $1000 \mathrm{~K}: 10.2-12 \mathrm{GPa}$ ) and elastic modulus (pristine samples: 115-127 GPa, after annealing at $1000 \mathrm{~K}: 126-137 \mathrm{GPa}$ ) occurred. The initially heterogeneous recrystallization process is accompanied by oxidation of iron, the related loss of hydrogen and induced stress fields in the bulk material, which cause internal and surface cracking after step-wise annealing from 800-1000 K. HRTEM imaging of the pristine material shows preserved nanometer-sized crystalline domains embedded in the amorphous matrix, despite the high degree of structural 
damage. The results show that hardness and elastic modulus are sensitive indicators for the structural reorganization process.

\section{Keywords}

Allanite, Radiation damage, Mechanical properties, Nanoindentation, Thermal annealing, Oxidation

\section{Acknowledgments}

This research was funded by the Deutsche Forschungsgemeinschaft (DFG, German Research Foundation) - BE 5456/2-1 (T.B. and C.E.R.). R.C.E. was supported by the U.S. Department of Energy through the Energy Frontier Research Center “Materials Science of Actinides” under Award Number DE-SC0001089. A.N. was supported by the U.S. Department of Energy Grant DE-FG02-97ER14749. L.A.G. acknowledges the support of the Natural Sciences and Engineering Research Council of Canada (NSERC), funding reference 06434. We thank Thomas Malcherek for sample orientation, Gregor Hofer and Warren Oliver for fruitful discussions, the Geological Survey of Norway (NGU) for a quick and helpful response concerning the age database of the NGU, Peter Stutz for sample preparation and Jan Cempírek, the Pacific Museum of Earth (UBC), and the Fersman Mineralogy Museum for samples (LB-1 and R1). The constructive comments and helpful suggestions of two anonymous reviewers are gratefully acknowledged.

\section{Introduction}

Allanite has a general formula ${ }^{\mathrm{A} 1}(\mathrm{Ca})^{\mathrm{A} 2}(R E E)^{\mathrm{M} 1, \mathrm{M} 2}(\mathrm{Al})_{2}{ }^{\mathrm{M} 3}\left(\mathrm{Fe}^{2+}\right)\left[\mathrm{SiO}_{4}\right]\left[\mathrm{Si}_{2} \mathrm{O}_{7}\right] \mathrm{O}(\mathrm{OH})$ and belongs to the allanite group of the epidote-supergroup (Armbruster et al. 2006, Bonazzi et al. 2009, Mills et al. 2009). Allanite can have a rare earth element (REE) oxide content of up to $26 \mathrm{wt} \%$ (Harlov et al. 2002) and therefore, has been historically mined for rare earth elements (e.g., Ehlmann et al. 1964, Maas et al. 1987). Furthermore, allanite has been used for geochronological dating (e.g. Catlos et al. 2000, Romer \& Siegesmund 2003, Gregory et al. 2007, McFarlane 2016, Fu et al. 2017). If Ce is the dominant REE it is designated as allanite-(Ce) (according to the Levinson rule) with composition $\mathrm{Ca}(\mathrm{Ce}, \mathrm{La}, \mathrm{Ca})\left(\mathrm{Fe}^{2+}, \mathrm{Fe}^{3+}\right)\left(\mathrm{Al}, \mathrm{Fe}^{3+}\right) \mathrm{Al}\left(\mathrm{Si}_{2} \mathrm{O}_{7}\right)\left(\mathrm{SiO}_{4}\right) \mathrm{O}(\mathrm{OH})$ (Ercit 2002, Armbruster et al. 2006). The crystal structure is monoclinic $\left(P 2{ }_{1} / m\right)$, composed of a framework of two types of edge-sharing octahedral chains (single M1 octrahedra chain and a multiple chain of M2 and peripheral M3 octahedra) cross-linked by $\mathrm{SiO}_{4}$ and $\mathrm{Si}_{2} \mathrm{O}_{7}$ groups (Fig. 1) (Dollase 1973). The M1 site can be occupied by $\mathrm{Al}, \mathrm{Fe}, \mathrm{Mg}, \mathrm{Mn}, \mathrm{Ti}, \mathrm{Cr}$, and V, and the M3 site by Fe, Mn, Mg, Al, Cu, Cr, and V, whereas the M2 site is usually only occupied by Al. The M3 octahedra’s corner links to the Si sites from polyhedral (A1 and A2) positions, which host Ca, Mn, and Na (A1), and Ce or other lanthanides, as well as actinides such as U and Th or other cations (e.g., Sr, Pb, and Cd) (A2) (Ercit 2002). A proton is attached to the $\mathrm{O} 10$ atom of the M2 octahedron by covalent bonding (Dollase 1973). The incorporated $U$ and/or Th cause the allanite to become amorphous or metamict due to alpha-decay events. During the alpha-decay an $\alpha$-particle $\left({ }_{2}^{4} \mathrm{He}^{2+}\right.$ nucleus) and a heavy recoil nucleus are generated (Ewing et al. 2000). The smaller $\alpha$-particle has higher energies ( 4.5-5.8 MeV for actinides) and a longer trajectory of $\sim 15-22 \mu \mathrm{m}$ compared to the recoil nucleus. Along its trajectory the $\alpha$-particle’s energy is dissipated by electronic excitations, displacing several hundreds of atoms by the end of its path. The heavier recoil nucleus, despite having a lower 
kinetic energy (70-100 keV) and a shorter trajectory of 30 - 40 nm, displaces several thousand atoms, creating a collision cascade mostly by elastic collisions (Ewing 2011).

Up to now, very little is known about the response of the mechanical properties of different mineral structures to $\alpha$-decay induced damage. Mechanical softening as a function of increasing radiation dose was observed by Chakoumakos et al. (1991) and Beirau et al. (2016a, 2018) in zircon. Annealing of radiation-damaged Ti-Nb-Ta oxides leads to an increase of the hardness during structural reorganization (Ewing 1973). Partially amorphous titanite shows an initial softening and subsequent increase of hardness and elastic moduli due to thermal treatment (Salje et al. 2011, Beirau et al. 2016b). In this study, the mineral allanite-(Ce), which can incorporate up to 5 wt\% $\mathrm{ThO}_{2}$, (Exley 1980, Gieré \& Sorensen 2004), was chosen because it contains structural $\mathrm{OH}^{-}$groups. Their general influence is of major interest as $\mathrm{OH}$ is assumed to act as a catalyst for thermally induced recrystallization processes in radiation-damaged minerals (Zhang et al. 2000).

The recrystallization behavior of radiation-damaged allanite was studied using powder XRD by Janeczek \& Eby (1993). They observed the first stage of thermally induced reorganization, related to partial recrystallization of the amorphous compound, in the temperature interval of 773 to $873 \mathrm{~K}$. Čobić et al. (2010) found that recrystallization in air resulted in partial recovery of allanite-(Ce) at $923 \mathrm{~K}$, followed by structural decomposition at higher temperatures, whereas hydrothermal treatment leads to an earlier and quicker reorganization process without evidence of structural decomposition. Annealing experiments in air showed a significant increase in the unit-cell parameter along the $c$ axis at $873 \mathrm{~K}-1073 \mathrm{~K}$ due to the loss of $\mathrm{H}^{+}$during $\mathrm{Fe}^{2+} \rightarrow \mathrm{Fe}^{3+}$ oxidation (Bonazzi \& Menchetti 1994). Vance and Routcliffe (1976) obtained a diffuse Laue pattern, showing no sharp spots, from one heavily damaged allanite after annealing at $673 \mathrm{~K}$, while two other samples showed no such behavior up to annealing temperatures of $1073 \mathrm{~K}$.

The purpose of this study is to investigate how the mechanical properties (i.e., elastic modulus and hardness) of radiation-damaged allanite-(Ce) are affected by a step-wise thermal treatment. To avoid the reported decomposition of allanite at higher temperatures (e.g., Janeczek \& Eby 1993, Čobić et al. 2010), the maximum temperature investigated was limited to $1000 \mathrm{~K}$. The onset of thermally induced, heterogeneous structural reorganization was revealed to occur at temperatures between 500 and $700 \mathrm{~K}$, as found by nanoindentation, synchrotron single-crystal XRD, and DSC measurements. In addition, mass spectrometry and ${ }^{57} \mathrm{Fe}$ Mössbauer spectroscopy enabled us to follow the coupled processes of iron oxidation and dehydration.

\section{Samples and Methods}

\section{Allanite-(Ce) samples}

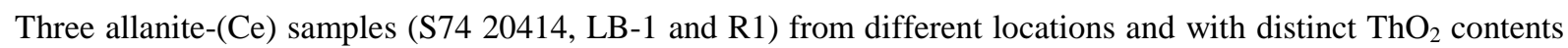
and ages were investigated (see Table 1), to enable a general statement on the recrystallization behavior of allanite. All crystals are opaque, black to black-brown, and have a vitreous luster. From each locality one larger sample was fragmented, while the fragments were thermally annealed individually.

Sample S74 20414 is from Hitterö Island in Norway. It has the highest REE content of 22 wt\% of which 11.47 wt \% is $\mathrm{Ce}_{2} \mathrm{O}_{3}$. It also has the lowest $\mathrm{ThO}_{2}$ content of only $0.55 \mathrm{wt} \%$ (see Table 2). Hetherington et al. (2008) dated xenotimes in the surrounding pegmatitic rocks using U-Pb-Th methods and obtained an age of $923 \pm 8 \mathrm{Ma}$. 
Sample LB-1 originates from pegmatitic rocks in Holmtjärn, Sweden. The total REE content is about 20 wt\%, however, only $7.06 \mathrm{wt} \%$ of this is $\mathrm{Ce}_{2} \mathrm{O}_{3}$. The $\mathrm{ThO}_{2}$ content is also slightly lower than in sample $\mathrm{R} 1,1.18 \mathrm{wt} \%$ (see Table 2), but with an age of 1520 Ma as determined using U-Pb-Th isotopes by Welin \& Blomqvist (1964). Sample R1 came from the collection of the Fersman Mineralogical Museum of the Russian Academy of Science in Moscow, Russian Federation. It is from Savvushka, Altai, Russian Federation. The R1 sample contains almost $20 \mathrm{wt} \%$ rare earth element oxides including $10.4 \mathrm{wt} \% \mathrm{Ce}_{2} \mathrm{O}_{3}$ and has an actinide oxide content of $1.59 \mathrm{wt} \% \mathrm{ThO}_{2}$ (see Table 2). The rocks in the area of the locality (northern Altai Mountains) have been dated to $243.5 \pm 2.1 \mathrm{Ma}$ using Rb-Sr isochrones from zircon (Vladimirov et al. 1997) and by ${ }^{40} \mathrm{Ar} /{ }^{39} \mathrm{Ar}$ dating on biotite to $244 \pm 1.1 \mathrm{Ma}$ (Gavryushkina et al. 2017).

Using the ages of 923 Ma for S74 20414, 1520 Ma for LB-1, and 244 Ma for R1, maximum life-time alpha-decay event doses $(D)$ of $3.5 \times 10^{18} \alpha$-decay/g, $2.0 \times 10^{19} \alpha$-decay/g, and $2.6 \times 10^{18} \alpha$-decay/g, respectively, can be calculated using

$$
D=6 \frac{c_{T h} \cdot N_{A}}{M_{232} \cdot 10^{6}}\left(e^{\lambda_{232} t}-1\right)
$$

with $c_{T h}$ being the thorium concentration, $N_{A}$ the Avogadro-constant, $M_{232}$ the mass of the ${ }^{232}$ Th isotope, $\lambda_{232}=4.93$ $\times 10^{-11} \mathrm{y}^{-1}$ the decay constant of ${ }^{232} \mathrm{Th}$ (from Firestone \& Shirley 1996), and $t$ the integration time (after Nasdala et al. 2001). As the uranium content was below detection limit, the doses were calculated only on the basis of the thorium content.

\section{Chemical analysis}

Electron microprobe measurements were completed on a CAMECA Camebax microbeam SX SEM system with an acceleration voltage of $15 \mathrm{keV}$, a probe current of $20 \mathrm{nA}$ and a beam size of $3 \mu \mathrm{m}$. Five to ten points distributed over one grain per sample were measured and the average was formed. A ZAF correction was used for intensitymass correlation. An X-PHI (Merlet 1994) routine was used for matrix correction. Standards used were almandine

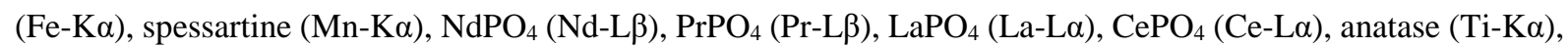

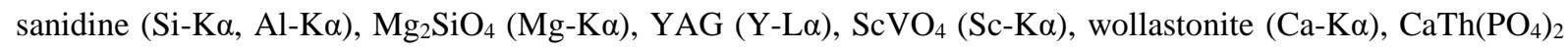

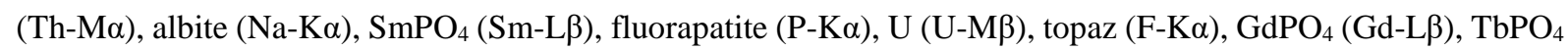
(Tb-L $\alpha$ ), DyPO 4 (Dy-L $\beta), \mathrm{HoPO}_{4}(\mathrm{Ho}-\mathrm{L} \beta)$, ErPO 4 (Er-L $\left.\alpha\right)$, zircon (Zr-L $\left.\alpha\right)$, EuPO 4 (Eu-L $\left.\beta\right)$, and vanadinite (Pb$\mathrm{M} \alpha, \mathrm{Cl}-\mathrm{K} \alpha$ ). Empirically determined correction factors were applied for F-Ce interference and other inter-REE interferences (see Škoda et al. 2015). These new results improve on the previous sample characterization of allanite R1 by Beirau et al. (2011).

\section{Synchrotron single-crystal X-ray diffraction}

Synchrotron single-crystal XRD measurements were carried out at beamline F1 (HASYLAB/DESY) on sample R1 using a kappa diffractometer equipped with a MarCCD165 detector. The sample-to-detector distance was 60 $\mathrm{mm}$ and the wavelength 0.71 Å. Progressive annealing studies were done with a $\mathrm{N}_{2}$ gas-stream heating device. The annealing time was set to 15 min for all temperatures, which was already sufficient to show early recrystallization. Ten grains with diameters of $<0.1 \mathrm{~mm}$ were prepared in quartz-glass capillaries and fixed with 
quartz-glass wool. Depending on the initial degree of structural damage and increasing recrystallization effects during annealing, step width and exposure times were varied between $0.5^{\circ}$ to $0.1^{\circ}$ and $20.0 \mathrm{~s}$ to $2.0 \mathrm{~s}$, respectively. For temperature-dependent analysis, the raw data were rescaled with respect to the primary beam intensity and varying exposure times (Paulmann et al. 2001). Corrections for external scattering were performed by averaging a range of background frames and subtracting the resulting background scattering from the scaled raw data scans. For each reflection an individual box was defined where the outer rim of the box was averaged as a background signal, excluding every pixel with intensities larger than $3 \sigma$. This background-intensity was then subtracted from the total intensity in the box thus yielding the intensity of the reflex in the frame. Through these peaks rocking curves were placed (see Inset in Fig. 2). To fit those curves a Lorentz-function was used. After each annealing step the samples were cooled to room temperature before measuring.

\section{Mössbauer spectroscopy}

${ }^{57} \mathrm{Fe}$ Mössbauer measurements were performed in standard transmission geometry on powdered samples in constant acceleration mode. The source was a $19 \mathrm{mCi}{ }^{57} \mathrm{CoRh}$ foil. Approximately $100 \mathrm{mg}$ of each sample were ground in an agate mortar to a fine powder, which was glued in a thin layer on a piece of paper filling a circle of ca. 1 inch. After the measurement of the pristine sample, the glue was dissolved in acetone and the clean powder was heated within $30 \mathrm{~min}$ up to the first annealing temperature $(700 \mathrm{~K})$ where it was held for $1 \mathrm{~h}$. Afterwards it was removed from the oven to cool down to ambient conditions. The thus annealed powder was glued again on a piece of paper and measured at room temperature. This intermediate annealing was repeated at $800 \mathrm{~K}, 900 \mathrm{~K}$, and $1000 \mathrm{~K}$ for each of the three samples. For the analysis of the obtained spectra the full Hamiltonian was solved. Sample thickness was taken into account using the approximations given by Mørup and Both (1975).

\section{X-ray powder diffraction}

Powder XRD patterns were recorded using a Panalytical X'Pert ${ }^{3}$ powder diffractometer with Bragg-Brentano geometry, a sample spinner, and $\mathrm{Cu}-\mathrm{K} \alpha$ radiation, operating at $45 \mathrm{kV}$ with a current of $40 \mathrm{~mA}$, a step-size of $0.01^{\circ}$ $2 \theta$, and a counting time of $150 \mathrm{~s}$ per step. The samples were ground in an agate mortar to a fine powder and stepwise annealed for $1 \mathrm{~h}$ in air at temperatures of 500, 600, 700, 800, 900, 950 and $1000 \mathrm{~K}$ and measured at room temperature after each annealing step.

\section{Transmission electron microscopy}

High-resolution imaging was done using a FEI Tecnai G2 F20 X-TWIN transmission electron microscope (TEM). The pristine samples were crushed to a fine powder, which was then dispersed in deionized water and deposited on a holey carbon-coated copper TEM grid. Images were collected using bright field mode at $200 \mathrm{kV}$. The highresolution images were analyzed using a Gatan Digital Micrograph.

\section{Nanoindentation}


The mechanical properties of bulk allanite-(Ce) samples (cut into cuboids of sizes: S74 20414: 2×1×0.5 cm, LB1: $\sim 2 \times 1 \times 1 \mathrm{~cm}$, and R1: $3 \times 1 \times 1 \mathrm{~cm}$ ) were measured using a Nanomechanics iNano nanoindenter equipped with a diamond Berkovich indenter tip, operating in the continuous stiffness mode (CSM). The indentations were made using a constant nominal strain rate of $0.2 \mathrm{~s}^{-1}$. Using CSM, the sample stiffness $(S)$ is measured continuously in the course of the loading process of the indenter (see Li \& Bhushan 2002; Oliver \& Pharr 2004). A small dynamic oscillation is imposed on the force or displacement signal, and the amplitude and phase of the corresponding signal is measured with a frequency-specific amplifier. The orientation-dependent measurements were performed on polished $(00 \overline{1})$ and $(0 \overline{1} 0)$ planes of the R1 sample. Indentations on sample LB-1 were done on the (11̄2) plane. Sample S74 20414 was unoriented. Various indents distributed over the entire sample surfaces (to ensure significant average results) were made on the pristine samples and after each annealing step. The instrument software calculated the hardness $(H)$ and the elastic modulus $(E)$ during the loading process according to Oliver \& Pharr (1992) with

$$
H=\frac{P}{A}
$$

where $P$ is the imposed load and $A$ the projected contact area between the indenter and the sample determined from the shape of the indenter and using the Oliver and Pharr method (Joslin \& Oliver 1990; Oliver \& Pharr 2004). The measured contact stiffness $(S)$ is related to the elastic properties of both the sample and indenter and the contact area through (Sneddon 1965)

$$
S=\beta \frac{2}{\sqrt{\pi}} E_{r} \sqrt{A}
$$

where $\beta$ is a constant depending on the indenter geometry (for Berkovich geometry $\beta=1.05$ ) (Oliver and Pharr 2004) and $E_{r}$ is the reduced modulus given by

$$
\frac{1}{E_{r}}=\frac{\left(1-v_{i}^{2}\right)}{E_{i}}+\frac{\left(1-v^{2}\right)}{E}
$$

where $E_{i}$ and $v_{i}$ are elastic modulus and Poisson's ratio of the indenter, respectively (for the diamond indenter $E_{i}=$ $1141 \mathrm{GPa}$ and $\left.v_{i}=0.07\right)$ and $E$ and $v$ are the elastic properties of the sample. $E_{r}$ considers that elastic displacement takes place in the sample and in the indenter (Oliver \& Pharr 2004). Fused silica was used as a reference material to calibrate the indenter. The $H$ and $E$ values shown in this study are averages from indentation depths of 150 to $250 \mathrm{~nm}$. A Poisson's ratio of 0.18 has been used for all samples. The samples were step-wise annealed in air for 1 $\mathrm{h}$ at the chosen temperatures of 500, 700, 800, 900 and $1000 \mathrm{~K}$. After each annealing step, they were cooled to room temperature before measuring.

\section{Thermal and evolved gas analyses}

The simultaneous DSC/TG (differential scanning calorimetry and thermogravimetry) analysis was performed with a Netzsch STA 449 C instrument. The pristine samples were ground into a fine powder of about $20 \mathrm{mg}$ and annealed in a Pt pan to $1000 \mathrm{~K}$ in air with a heating rate of $10 \mathrm{~K} / \mathrm{min}$. Mass spectrometry (MS) to determine the evolved gases from room temperature to $1000 \mathrm{~K}$ was done using a QMS 403D Aeolos Netzsch instrument.

\section{Results and discussion}

\section{Pristine radiation-damaged allanite-(Ce)}


Electron microprobe analysis revealed a relatively homogeneous chemical composition for allanite-(Ce) sample S74 20414, while samples LB-1 and R1 show small heterogeneities in their REE and Fe distribution (Table 2 and supplementary material). Initial $\mathrm{Fe}^{3+} / \mathrm{Fe}^{2+}$ ratios of 27:73 (S74 20414), 47:53 (LB-1), and 50:50 (R1), were measured with Mössbauer spectroscopy (see Table 3). In Figure 3 the Mössbauer spectra of the pristine samples and after step-wise annealing are shown. According to the ideal structure of allanite, Fe occupies the crystallographic sites M1 and M3. On both sites, Fe can be incorporated as 2+ or 3+. Therefore, four different subspectra for the four Fe species are expected to be present, which add up to the measured spectrum. Each subspectrum is characterized by a doublet, indicating that the Fe atoms are nonmagnetic, with characteristic values for center shift and quadrupole splitting. The relative intensities of the different subspectra correspond to the number of different Fe atoms. The result of such a fit is not fully satisfying, because there are deviations of the calculated spectra from the measured ones. This is not surprising, because due to the rather high $\alpha$-doses the structure is heavily disturbed. Whereas well crystallized allanite spectra show four sharp peaks, the concrete spectra show only three rather broad peaks with decreasing intensity, going from the negative to the positive velocity range. For sample S74 20414 the intensity of the middle peak (Fig. 3b, peak 2) is less pronounced then for the other two samples (Fig. 3a and c). A similar three peak shape of the Mössbauer spectrum was observed by Malczewsik \& Grabias (2008) for an allanite (ALL3) from Franklin and Sussex County, New Jersey, which had absorbed a rather high $\alpha$-dose. To explain their spectrum they added another two subspectra corresponding to a second M3 site with slightly different hyperfine parameters, due to different distortion of the M3 octahedra (Malczewski \& Grabias 2008). This new M3 site can also be occupied by both $\mathrm{Fe}^{2+}$ and $\mathrm{Fe}^{3+}$, leading to two further subspectra. A fit according to this model gives better coincidence between the calculated and measured spectra. Concerning the amount and ratio of $\mathrm{Fe}^{2+}$ and $\mathrm{Fe}^{3+}$, both fits - with four and six subspectra - give within the error (see Table 3) the same results. Therefore, in Fig. 3 only the calculated spectra obtained with the six subspectra fits are shown. The hyperfine parameters of the pristine samples obtained by the fit are very similar to those obtained for the ALL3 sample by Malkczewski \& Grabias (2008).

The high degree of long-range structural disorder due to radiation-damage caused by incorporated $\mathrm{ThO}_{2}$ is indicated by very broad amorphous background features in powder XRD patterns $\left(\sim 25-35^{\circ} 2 \theta\right)$ of the pristine samples (Fig. 4). Nevertheless, a broadened weak allanite Bragg signal can be detected between $\sim 30-31^{\circ} 2 \theta$ in all three samples (cited as (113) by Čobić et al. 2010, also observed by Janeczek \& Eby 1993, and Hoshino et al. 2005). This is in excellent agreement with HRTEM showing an overall amorphous matrix with small preserved crystalline domains (Fig. 5) which function as seed crystals leading to a heterogeneous recrystallization process (discussed in the next section). Synchrotron single-crystal XRD measurements of sample R1 also indicate an initially highly disordered structure, showing only a few weak and broad Bragg signals (see example in Fig. 2). Sample LB-1 has the highest degree of structural order of all investigated samples as it shows the most preserved Bragg maxima according to powder XRD (Fig. 4). This is confirmed by the Mössbauer results, as the FWHM (Full Width at Half Maximum) of the peaks of the subspectra of the pristine samples is smallest for sample LB-1. The calculated maximum radiation dose (Table 1) would indicate this sample to have the least structural order of all three samples, which leads to the assumption that allanite LB-1 has experienced an event that led to its (partial) recrystallization at some point. Such could be a geological event that leads to higher temperatures in the area like a granite intrusion (Ödman 1939).

No orientation dependence for loading perpendicular to the $(00 \overline{1})$ and $(0 \overline{1} 0)$ crystallographic planes of sample $\mathrm{R} 1$ of the indentation hardness $(9.3 \pm 0.2 \mathrm{GPa}$ and $9.3 \pm 0.3 \mathrm{GPa}$, respectively) and elastic modulus (127.0 \pm 1.6 
GPa and $127.2 \pm 3.2 \mathrm{GPa}$, respectively) could be detected (Tables 4 and 5, Fig. 6). This is the result of amorphization that renders the mechanical properties isotropic, which has also been observed for natural, highly radiation-damaged zircon (Beirau et al. 2016a). The indentation hardness of samples LB-1 and S74 20414 was found to be $8.8 \pm 0.5 \mathrm{GPa}$ and $8.2 \pm 0.1 \mathrm{GPa}$, respectively, and the elastic modulus $123.2 \pm 5.7 \mathrm{GPa}$ and $115.3 \pm$ 2.1 GPa, respectively (Tables 4 and 5). Sample R1 shows the highest hardness and elastic modulus values of the three investigated samples which is in agreement with the fact that it has experienced the lowest radiation dose (Table 1). However, as sample LB-1 showed the highest structural order in the powder XRD patterns (Fig. 4) indicating less structural damage (see above), but with $H$ and $E$ values close to R1 (Tables 4 and 5, Fig. 6). Therefore, influences from differences in the chemical composition (Table 3) cannot be excluded.

\section{Effect of thermal annealing in air}

Mass spectrometry indicated an increase of $\mathrm{OH} / \mathrm{H}_{2} \mathrm{O}$ in the analyzed air gas stream during annealing of sample R1 in the region of $\sim 350-525 \mathrm{~K}$ (maximum $\sim 400 \mathrm{~K}$ ) (Fig. 7b) that is probably due to the loss of water adhering to the surface at these lower annealing temperatures. This increase is only slightly visible for sample LB-1 (Fig. 8b) and not at all for sample S74 20414 (Fig. 9b). Above $\sim 475 \mathrm{~K}$ the onset of a very broad exothermic process is visible in the DSC signals of all three samples, accompanied by a steady slight weight loss (Figs. 7,8 and 9a). This is in good agreement with the synchrotron XRD results of several analyzed grains of sample R1. They show an increase of the integrated intensity and decrease of the FWHM of the exemplary Bragg maxima (231) (chosen due to his initially sufficient intensity/background ratio) after step-wise annealing > $500 \mathrm{~K}$ (see exemplary Fig. 2). This indicates the healing of defects and an increase in grain size, hence the reestablishment of long-range order in the system leading to smaller FWHM values. Not all grains, from the same sample, investigated by synchrotron XRD, showed these early steps of structural reestablishment. Heterogeneity of the degree of structural disorder in the fragments of R1 was also indicated by differences in peak intensities and FWHM. This heterogeneity seems to be very local, as no effect on a larger scale could be observed. In a similar temperature region ( 575-610 K) all DSC signals show a sharper maximum, while TG analysis shows a stronger mass loss (Figs. 7,8 and 9a). At these

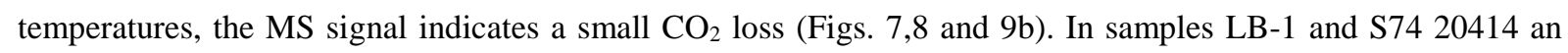
additional, larger peak at $\sim 850-1000 \mathrm{~K}$ can be observed. However, in sample R1 only the smaller peak is present at temperatures of $\sim 500-700 \mathrm{~K}$ and none at higher temperatures. The powder XRD pattern of sample S74 20414 shows a Bragg signal at $29^{\circ} 2 \theta$ that can be attributed to calcite, which vanishes after annealing at temperatures of 900 K (Fig. 4a). Calcite inclusions in allanite have been described by Papunen and Lindsjö (1972), and the temperature at which $\mathrm{CO}_{2}$ is released (Figs. 8 and 9b) in these samples corresponds well to the collapse of weathered calcite which starts thermal dissociation at around 875-975 K (Földvári 2011). DSC/TG and MS measurements show the highest $\mathrm{CO}_{2}$ loss in sample S74 20414 (Fig. 9b), with slightly fewer intensities in sample LB-1 (Fig. 8b). Sample R1 shows comparably little loss in $\mathrm{CO}_{2}$ (Fig. 7b). The $\mathrm{OH}$ and $\mathrm{H}_{2} \mathrm{O}$ loss are highest in sample LB-1, and least in sample R1 as discussed below in further detail (see Figs. 7, 8 and 9b).

The mechanical properties of all three samples provide evidence for structural reorganization after annealing at $700 \mathrm{~K}$, showing a noticeable increase of the elastic modulus to $122.4 \pm 1.8 \mathrm{GPa}, 128.9 \pm 6.8 \mathrm{GPa}, 137.1 \pm 2.0 \mathrm{GPa}$

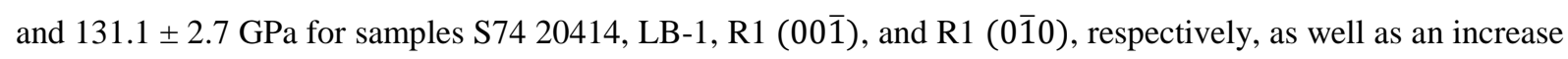
in hardness to 9.2 $\pm 0.1 \mathrm{GPa}, 10.3 \pm 0.7 \mathrm{GPa}, 10.2 \pm 0.2 \mathrm{GPa}$ and $9.3 \pm 0.3 \mathrm{GPa}$ for samples S74 20414, LB-1, R1 $(00 \overline{1})$, and R1 $(0 \overline{1} 0)$, respectively (see Fig. 6, Tables 4,5$)$. The increase in hardness and modulus indicates an 
increasing overall structural integrity and bond strengthening due to thermal treatment. The powder XRD measurements, more sensitive to long-range periodicity, show no clear evidence for this early recrystallization process. That is in good agreement with previous results (Janeczek \& Eby 1993, Čobić et al 2010). One could also expect masking effects of higher amounts of more damaged material in the investigated powders, superimposing the signals from already recrystallizing, comparably small, less-damaged domains.

Starting at annealing temperatures of $\sim 650 \mathrm{~K}$ an increase in hydrogen in the analyzed gas stream was detected by MS (measured as masses 17 and 18 which were assigned to $\mathrm{OH}$ and $\mathrm{H}_{2} \mathrm{O}$, respectively) with a maximum around $880 \mathrm{~K}$ (Figs. 7, 8 and 9b). This is accompanied by iron oxidation $\left(\mathrm{Fe}^{2+} \rightarrow \mathrm{Fe}^{3+}\right.$ ) observed by Mössbauer spectroscopy, as with increasing annealing temperature the peak at the highest positive velocity (Fig. 2, peak 3) vanishes. Due to the position of this peak, it can be attributed to $\mathrm{Fe}^{2+}$ high spin. Starting with $\mathrm{Fe}^{2+} / \mathrm{Fe}^{3+}$ ratios of 2.68, 1.11, and 1.00 for samples S74 20414, LB-1, and R1, respectively, the ratio decreased with increasing annealing temperature, reaching 0 for samples R1 and S74 20414 between $800 \mathrm{~K}$ and $900 \mathrm{~K}$, whereas for sample LB-1 16.1\% of $\mathrm{Fe}^{2+}$ was still present after annealing at $1000 \mathrm{~K}$ (Table 3). This oxidation is an increasingly strong endothermic process, visible in the DSC signal starting around $\sim 700 \mathrm{~K}$ until $\sim 1000 \mathrm{~K}$ when all Fe $\mathrm{F}^{2+}$ is oxidized except for that in sample LB-1 (Figs. 7, 8 and 9a). One can expect this process to superimpose on the ongoing exothermic structural reorganization. These findings are in excellent agreement with the assumption that hydrogen loss serves as charge compensation for the iron oxidation (Dollase 1971; Bonazzi \& Menchetti 1994) which has been reported to start > $673 \mathrm{~K}$ and be complete around $973 \mathrm{~K}$ for allanite (Dollase 1971; see also Gieré \& Sorensen 2004).

Step-wise annealing above $900 \mathrm{~K}$ causes a sharpening of the (113) Bragg-reflex in the powder XRD patterns (Fig. 4). After annealing at $900 \mathrm{~K}$ the hardness and modulus of sample LB-1 show a further increase to $11.4 \pm 0.8 \mathrm{GPa}$ and 149.6 \pm 9.5 GPa, respectively. Even higher values are seen after annealing at $1000 \mathrm{~K}$ with a hardness of 12.0 $\pm 0.9 \mathrm{GPa}$ and an elastic modulus of $163.0 \pm 12 \mathrm{GPa}$ (Fig. 6, Tables 4, 5). This trend is not visible for samples S74 20414 and R1 (Fig. 6, Tables 4,5). The higher $\mathrm{OH}^{-}$content of sample LB-1 could be the cause of the more rapid recrystallization and the stronger increases in hardness and modulus. Čobić et al. (2010) also found quicker recrystallization in allanite samples that were annealed under hydrothermal conditions. Furthermore, the induced interior stress caused by heterogeneous recrystallization and hydrogen loss leads to internal and surface cracking at higher temperatures (visible under the microscope and in the depth evolution of the mechanical properties). This hampers the precise determination of $H$ and $E$ values after step-wise annealing in the region of 800 up to $1000 \mathrm{~K}$, as fracturing leads to a decrease of the mechanical properties (Walsh 1965). One can expect the mechanical properties to increase further with increasing overall crystallinity, but due to the internal failure of the material they become partially strongly disturbed, leading to larger errors. Nevertheless, despite the reducing effect of fracturing, an increase (LB-1) or at least an overall plateau-like behavior (R1 and S74 20414) is visible for $H$ and $E$ at higher annealing temperatures. However, the difference in chemical composition, (e.g., $\mathrm{Ce}_{2} \mathrm{O}_{3}$ makes up over half the REE content in samples S74 20414 and R1 and only a little over a third in sample LB-1 (Table 2 and supplementary material)), might also have an influence on the recrystallization behavior, as well as the difference in the initial degree of disorder.

\section{Conclusions}


Thermal treatment of radiation-damaged allanite-(Ce) leads to heterogeneous recrystallization, due to the presence of less-damaged domains in the material. The recrystallization process starts around $550 \mathrm{~K}$, as seen in the synchrotron data, and goes on continuously. Low-temperature annealing at $700 \mathrm{~K}$ leads to an increase in the mechanical properties of about $5 \%$ in the elastic modulus and about $10 \%$ in the hardness in all investigated samples. This further indicates a restoration of long-range order in the structure due to the reorganization process. In the temperature region of $\sim 700$ to $1000 \mathrm{~K}$ the structural $\mathrm{Fe}^{2+}$ oxidizes in air, which is coupled to the loss of hydrogen. The revealed adverse effect of internal and surface cracking reaches a maximum after annealing at 900 $\mathrm{K}$, when almost all $\mathrm{Fe}^{2+}$ is oxidized, and the most hydrogen is lost. The elastic modulus is more sensitive to fracturing than hardness. The initial maximum alpha-radiation dose (as calculated according to Equ. 1, see Table 1) as well as the assumed degree of structural damage (as estimated from powder XRD, see Fig. 4) do not seem to correlate completely with the $H$ and $E$ order of the three samples. Although a comparison of samples R1 and S74 20414 show higher $H$ and $E$ values with higher structural order, sample LB-1, showing initially the highest degree of structural order, has intermediate $E$ and $H$ values compared to the other two samples. It is, therefore, assumed that differences in chemistry and/or orientation also have a noticeable impact. Nevertheless, despite their differences in chemistry, radiation damage and orientation, all three samples showed an increase in $H$ and $E$ at the same annealing temperature (700 K) thus indicating a similar behavior in the recrystallization offset. The higher $\mathrm{OH}^{-}$content in sample LB-1 seems to act as a catalyst in the structural reorganization process, as assumed by Zhang et al. (2010) for zircon, leading to a stronger increase in the mechanical properties at higher temperatures (i.e. during the oxidation/dehydration process). In conclusion, the mechanical properties ( $E$ and $H$ ) are sensitive indicators of the degree of structural reorganization during the annealing process.

\section{References}

Armbruster T, Bonazzi P, Akasaka M, Bermanec V, Chopin C, Gieré R, Heuss-Assbichler S, Liebscher A, Menchetti S, Pan Y, Pasero M (2006) Recommended nomenclature of epidote-group minerals. Eur J Mineral 18:551-567. https://doi.org/10.1127/0935-1221/2006/0018-0551

Beirau T, Nix WD, Bismayer U, Boatner LA, Isaacson SG, Ewing RC (2016a) Anisotropic properties of zircon and the effect of radiation damage. Phys Chem Minerals 43:627-638. https://doi.org/10.1007/s00269-016-0822-9 Beirau T, Nix WD, Ewing RC, Pöllmann H, Salje EKH (2018) Radiation-damage-induced transitions in zircon: Percolation theory applied to hardness and elastic moduli as a function of density. Appl Phys Let 112:201901. https://doi.org/10.1063/1.5030626

Beirau T, Nix WD, Ewing RC, Schneider GA, Groat LA, Bismayer U (2016b) Mechanical properties of natural radiation-damaged titanite and temperature-induced structural reorganization: A nanoindentation and Raman spectroscopic study. Am Mineral 101:399-406. http://dx.doi.org/10.2138/am-2016-5433

Beirau T, Paulmann C, Bismayer U (2011) Recrystallization of metamict allanite. Mineral Mag 75(4):2393-2399. https://doi.org/10.1180/minmag.2011.075.4.2393

Bonazzi P, Holtstam D, Bindi L, Nysten P, Capitani GC (2009) Multi-analytical approach to solve the puzzle of an allanite-subgroup mineral from Kesebol, Västra Götaland, Sweden. Am Mineral 94:121-134. https://doi.org/10.2138/am.2009.2998

Bonazzi P, Menchetti S (1994) Structural variations induced by heat treatment in allanite and REE-bearing piemontite. Am Mineral 79:1176-1184. 
Catlos EJ, Sorensen SS, Harrison TM (2000) Th-Pb ion-microprobe dating of allanite. Am Mineral 85:633-648. https://doi.org/10.2138/am-2000-5-601

Chakoumakos BC, Oliver WC, Lumpkin GR, Ewing RC (1991) Hardness and elastic modulus of zircon as a function of heavy-particle irradiation dose: I. In situ $\alpha$-decay event damage. Radiat Eff Defect S 118(4):393-403. Čobić A, Bermanec V, Tomašić N (2010) The hydrothermal recrystallization of metamict allanite-(Ce). Can Mineral 48:513-521. https://doi.org/10.3749/canmin.48.3.513

Dollase WA (1971) Refinement of the crystal structure of epidote, allanite and hancockite. Am Mineral 56:447464.

Dollase WA (1973) Mössbauer spectra and iron distribution in the epidote-group minerals. Z Kristallogr 138:4163

Ehlmann AJ, Walper JL, Williams J (1964) A new, baringer hill-type, rare-earth pegmatite from the central mineral region, Texas. Econ Geol 59:1348-1360. https://doi.org/10.2113/gsecongeo.59.7.1348

Ercit TS (2002) The mess that is “allanite". Can Mineral 40:1411-1419. https://doi.org/10.2113/gscanmin.40.5.1411

Exley RA (1980) Microprobe studies of REE-rich accessory minerals: Implications for Skye Granite petrogenesis and REE mobility in hydrothermal systems. Earth Planet Sc Lett 48:97-110

Ewing RC (1973) Vickers Hardness and Reflectance Determination for Metamict $\mathrm{AB}_{2} \mathrm{O}_{6}$-Type Rare Earth Ti-NbTa Oxides. Am Mineral 58:942-944

Ewing RC, Meldrum A, Wang LM, Wang SX (2000) Radiation-induced amorphization. Rev Mineral Geochem 39:319-361.

Ewing RC (2011) Actinides and radiation effects: impact on the back-end of the nuclear fuel cycle. Mineral Mag 75(4):2359-2377. https://doi.org/10.1180/minmag.2011.075.4.2359

Firestone RB, Shirley VS (1996) Table of isotopes 2. Wiley, New York

Földvári M (2011) Handbook of thermogravimetric system of minerals and its use in geological practice. Occasional Papers of the Geological Institute of Hungary, Volume 213.

Fu Y, Sun X, Li D, Lin H, Lai C (2017) LA-ICP-MS U-Th-Pb Dating and Trace Element Geochemistry of Allanite: Implications on the Different Skarn Metallogenesis between the Giant Beiya Au and Machangqing Cu-Mo-(Au) Deposits in Yunnan, SW China. Minerals 7:251. https://doi.org/10.3390/min7120251

Gavryushkina OA, Travin AV, Kruk NN (2017) Duration of granitoid magmatism in peripheral parts of large igneous provinces (Based on ${ }^{40} \mathrm{Ar} /{ }^{39} \mathrm{Ar}$ isotopic studies of Altai Permian-Triassic granitoids. Geodynamics Tectonophysics 8(4):1035-1047. https://doi.org/10.5800/GT-2017-8-4-0331

Gieré R, Sorensen SS (2004) Allanite and Other REE-Rich Epidote-Group Minerals. Rev Mineral Geochem 56:431-493. https://doi.org/10.2138/gsrmg.56.1.431

Gregory CJ, Rubatto D, Allen CM, Williams IS, Hermann J, Ireland T (2007) Allanite micro-geochronology: A LA-ICP-MS and SHRIMP U-Th-Pb study. Chem Geol 245:162-182. https://doi.org/10.1016/j.chemgeo.2007.07.029

Harlov DE, Andersson UB, Förster H-J, Nyström JO, Dulski P, Broman C (2002) Apatite-monazite relations in the Kiirunavaara magnetite-apatite ore, northern Sweden. Chem Geol 191:47-72. https://doi.org/10.1016/S00092541(02)00148-1 
Hetherington CJ, Jercinovic MJ, Williams ML, Mahan K (2008) Understanding geological processes with xenotime: Composition, chronology, and a protocol for electron probe microanalysis. Chem Geol 254: $133-147$. https://doi.org/10.1016/j.chemgeo.2008.05.020

Hoshino M, Kimata M, Nishida N, Kyono A, Shimizu M, Takizawa S (2005) The chemistry of allanite from the Daibosatsu Pass, Yamanashi, Japan. Mineral Mag 69(4):403-423. https://doi.org/10.1180/0026461056940259

Janeczek J, Eby RK (1993) Annealing of Radiation Damage in Allanite and Gadolinite. Phys Chem Minerals 19:343-356. https://doi.org/10.1007/BF00202971

Joslin DL, Oliver WC (1990) A new method for analyzing data from continuous depth-sensing microindentation tests. J Mater Res 5(1):123-126

Kartashov PM, Ferraris G, Ivaldi G, Sokolova E, McCammon CA (2002) Ferriallanite-(Ce), $\mathrm{CaCeFe}^{3+} \mathrm{AlFe}^{2+}\left(\mathrm{SiO}_{4}\right)\left(\mathrm{Si}_{2} \mathrm{O}_{7}\right) \mathrm{O}(\mathrm{OH})$, a new member of the epidote group: Description, X-ray and Mössbauer study. Can Mineral 40:1641-1648

Li X, Bhushan B (2002) A review of nanoindentation continuous stiffness measurement technique and its applications. Mater Charact 48:11-36. https://doi.org/10.1016/S1044-5803(02)00192-4

Maas R, McCulloch MT, Campbell IH (1987) Sm-Nd Isotope Systematics in Uranium-Rare Earth Element Mineralization at the Mary Kathleen Uranium Mine, Queensland. Econ Geol 82:1805-1826. https://doi.org/10.2113/gsecongeo.82.7.1805

Malczewski D, Grabias A (2008) 57Fe Mössbauer Spectroscopy of Radiation Damaged Allanites. Acta Phys Pol A 114(6):1683-1690. https://doi.org/10.12693/APhysPolA.114.1683

McFarlane CRM (2016) Allanite U-Pb geochronology by 193 nm LA ICP-MS using NIST610 glass for external calinration. Chem Geol 438:91-102. http://dx.doi.org/10.1016/j.chemgeo.2016.05.026

Merlet C (1994) An Accurate Computer Correction Program for Quantitative Electron Probe Microanalysis. Microchim Acta 114/115:363-376

Mills SJ, Hatert F, Nickel EH, Ferraris G (2009) The standardisation of mineral group hierarchies: application to recent nomenclature proposals. Eur J Mineral 21:1073-1080. https://doi.org/10.1127/0935-1221/2009/0021-1994 Mørup S, Both E (1975) Interpretation of Mössbauer spectra with broadened lines. Nuclear Instruments and Methods 124(2): 445-448. https://doi.org/10.1016/0029-554X(75)90595-9

Nasdala L, Wenzel M, Vavra G, Irmer G, Wenzel T, Kober B (2001) Metamictisation of natural zircon: accumulation versus thermal annealing of radioactivity-induced damage. Contrib Mineral Petrol 141:125-144. http://dx.doi.org/10.1007/s004100000235

Ödman, OH (1939) The Gold-Copper-Arsenic Ore at Holmtjärn, Skellefte District, N. Sweden. Geol Foren Stock For 61(1):91-111. http://dx.doi.org/10.1080/11035893909446035

Oliver WC, Pharr GM (1992) An improved technique for determining hardness and elastic modulus using load and displacement sensing indentation experiments. J Mater Res 7(6):1564-1583. https://doi.org/10.1557/JMR.1992.1564

Oliver WC, Pharr GM (2004) Measurement of hardness and elastic modulus by instrumented indentation: Advances in understanding and refinements to methodology. J Mater Res 19(1):3-20. https://doi.org/10.1557/jmr.2004.19.1.3

Papunen H, Lindsjö O (1972) Apatite, monazite and allanite: Three rare earth minerals from Korsnäs, Finland. Bul Geol Soc Finl 44:123-129 
Paulmann C, Kurtz R, Bismayer U (2001) Software development for studies of diffuse scattering using CCDdetectors and synchrotron radiation sources. Nucl Instrum Meth A 467-468:1113-1116

Romer RL, Siegesmund S (2003) Why allanite may swindle about its true age. Contrib Mineral Petrol 146:297307. https://doi.org/10.1007/s00410-003-0494-6

Salje EKH, Safarik DJ, Lahley JC, Groat LA, Bismayer U (2011) Elastic softening of metamict titanite CaTiSiOs: Radiation damage and annealing

Škoda R, Plášil J, Jonsson E, Čopjaková R, Langhof J, Galiová MV (2015) Redefinition of thalénite-(Y) and discredition of fluorthelénite-(Y): A reinvestigation of type material from the Österby pegmatite, Dalarna, Sweden, and from additional localities. Mineral Mag 79(4):965-983. https://doi.org/10.1180/minmag.2015.079.4.07

Sneddon IN (1965) The relation between load and penetration in the axisymmetric buissinesq problem for a punch of arbitrary profile. Int J Eng Sci 3:47-57. https://doi.org/10.1016/0020-7225(65)90019-4

Vance ER, Routcliffe P (1976) Heat treatment of some metamict allanites. Mineral Mag 40:521-523.

Vladimirov AG, Ponomareva AP, Shokalskii SP, Khalilov VA, Kostitsyn YA, Ponomarchuk VA, Rudney SN, Vystavnoi SA, Kruk NN, Titov AV (1997) Late Paleozoic early Mesozoic granitoid magmatism in Altai. Geologiya \& Geofizika 38:715-729

Walsh JB (1965) The Effect of Cracks on the Uniaxial Elastic Compression. J Geophys Res 70(2):399-411

Welin E, Blomqvist G (1964) Age measurements on radioactive minerals from Sweden. Geol Foren Stock For 86(1):33-50. http://dx.doi.org/10.1080/11035897.1964.9626366

Zhang M, Salje EKH, Malcherek T, Bismayer U, Groat LA (2000) Dehydration of metamict titanite: an infrared spectroscopic study. Can Mineral 38:119-130.

\section{Tables}

Table 1 Location, age, wt $\% \mathrm{ThO}_{2}$ (from EMPA measurements, see Table 2) and dose (calculated after equation 1) for the investigated allanite-(Ce) samples. *Hetherington et al. (2008), **Welin \& Blomqvist (1964), ***Gavryushkina et al. (2017) and Vladimirov et al. (1997)

\begin{tabular}{|l|l|l|l|l|}
\hline Sample & Location & Age [Ma] & wt\% $\mathrm{ThO}_{2}$ & dose [a-decay/g] \\
\hline S74 20414 & Hitterö, Norway & $923 \pm 8^{*}$ & 0.55 & $\begin{array}{l}3.5 \times 10^{18} \pm 4.5 \mathrm{x} \\
10^{15}\end{array}$ \\
\hline LB-1 & & & & $2.0 \times 10^{19}$ \\
\hline R1 & Holmtjärn, Sweden & $1520^{* *}$ & 1.18 & $\begin{array}{l}2.6 \times 10^{18} \pm 1.7 \times \\
10^{15}\end{array}$ \\
\hline
\end{tabular}

Table 2 Electron microprobe compositions of allanite-(Ce) samples S74 20414, LB-1 and R1 (averaged over five to ten points on each sample)

\begin{tabular}{|c|c|c|c|c|c|c|c|}
\hline \multirow{2}{*}{ Oxide } & \multicolumn{3}{|c|}{$\mathrm{wt} \%$} & \multirow{2}{*}{ Oxide } & \multicolumn{3}{|c|}{$\mathrm{wt} \%$} \\
\hline & S74 20414 & LB-1 & R1 & & S74 20414 & LB-1 & $\mathrm{R} 1$ \\
\hline $\mathrm{SiO}_{2}$ & 31.78 & 31.70 & 31.73 & $\mathrm{MnO}$ & 0.31 & 0.39 & 2.71 \\
\hline $\mathrm{Al}_{2} \mathrm{O}_{3}$ & 14.30 & 15.16 & 13.43 & $\mathrm{Cl}$ & 0.08 & 0.13 & n.d. \\
\hline $\mathrm{FeO}^{*}$ & 12.79 & 12.12 & 16.39 & $\mathrm{PbO}$ & n.d. & 0.07 & n.d. \\
\hline $\mathrm{Ce}_{2} \mathrm{O}_{3}$ & 11.47 & 7.06 & 10.38 & $\mathrm{Na}_{2} \mathrm{O}$ & n.d. & 0.14 & n.d. \\
\hline $\mathrm{CaO}$ & 10.94 & 11.15 & 10.96 & $\mathrm{Sm}_{2} \mathrm{O}_{3}$ & n.d. & 1.73 & n.d. \\
\hline $\mathrm{La}_{2} \mathrm{O}_{3}$ & 7.00 & 2.63 & 5.73 & $\mathrm{Y}_{2} \mathrm{O}_{3}$ & n.d. & 1.29 & 0.15 \\
\hline $\mathrm{Nd}_{2} \mathrm{O}_{3}$ & 2.88 & 4.97 & 2.20 & $\mathrm{Gd}_{2} \mathrm{O}_{3}$ & n.d. & 1.19 & n.d. \\
\hline $\mathrm{MgO}$ & 1.87 & 0.27 & 0.58 & $\mathrm{Sc}_{2} \mathrm{O}_{3}$ & n.d. & 0.30 & 0.19 \\
\hline $\mathrm{TiO}_{2}$ & 0.94 & 0.27 & 0.81 & $\mathrm{Dy}_{2} \mathrm{O}_{3}$ & n.d. & 0.29 & n.d. \\
\hline $\mathrm{Pr}_{2} \mathrm{O}_{3}$ & 0.70 & 1.09 & 0.87 & $\mathrm{~Tb}_{2} \mathrm{O}_{3}$ & n.d. & 0.11 & n.d. \\
\hline
\end{tabular}




\begin{tabular}{|l|l|l|l|l|l|l|l|}
\hline $\mathrm{ThO}_{2}$ & 0.55 & 1.18 & 1.59 & Total & 95.61 & 93.24 & 97.72 \\
\hline
\end{tabular}

*all $\mathrm{Fe}$ is assumed to be $\mathrm{Fe}^{2+}$ for the purpose of the chemical analysis

Table 3 Change of amounts $\mathrm{Fe}^{2+}$ and $\mathrm{Fe}^{3+}$ with annealing temperature for samples S74 20414, LB-1, and R1 from Mössbauer spectroscopic analysis (see also Fig. 3)

\begin{tabular}{|l|l|l|l|l|l|l|l|l|l|}
\hline $\begin{array}{l}\text { Temperature } \\
{[\mathrm{K}]}\end{array}$ & \multicolumn{3}{l|}{ S74 20414} & \multicolumn{2}{l|}{ LB-1 } & \multicolumn{2}{l|}{$\mathrm{R} 1$} \\
\hline & $\begin{array}{l}\mathrm{Fe}^{2+} \\
{[\%]}\end{array}$ & $\begin{array}{l}\mathrm{Fe}^{3+} \\
{[\%]}\end{array}$ & $\mathrm{Fe}^{2+} / \mathrm{Fe}^{3+}$ & $\begin{array}{l}\mathrm{Fe}^{2+} \\
{[\%]}\end{array}$ & $\begin{array}{l}\mathrm{Fe}^{3+} \\
{[\%]}\end{array}$ & $\mathrm{Fe}^{2+} / \mathrm{Fe}^{3+}$ & $\begin{array}{l}\mathrm{Fe}^{2+} \\
{[\%]}\end{array}$ & $\begin{array}{l}\mathrm{Fe}^{3+} \\
{[\%]}\end{array}$ & $\mathrm{Fe}^{2+} / \mathrm{Fe}^{3+}$ \\
\hline pristine (300) & $73 \pm 3$ & $27 \pm 3$ & 2.68 & $53 \pm 3$ & $47 \pm 3$ & 1.11 & $50 \pm 3$ & $50 \pm 3$ & 1.00 \\
\hline 700 & $42 \pm 3$ & $58 \pm 3$ & 0.74 & $17 \pm 3$ & $84 \pm 3$ & 0.20 & $35 \pm 3$ & $65 \pm 3$ & 0.54 \\
\hline 800 & $7 \pm 3$ & $93 \pm 3$ & 0.79 & $13 \pm 3$ & $87 \pm 3$ & 0.15 & $15 \pm 3$ & $85 \pm 3$ & 0.18 \\
\hline 900 & 0 & 100 & 0 & $14 \pm 3$ & $86 \pm 3$ & 0.16 & 0 & 100 & 0 \\
\hline 1000 & 0 & 100 & 0 & $16 \pm 3$ & $84 \pm 3$ & 0.19 & 0 & 100 & 0 \\
\hline
\end{tabular}

Table 4 Hardness values of allanite-(Ce) samples S74 20414, LB-1, and R1 (two orientations), after annealing at different temperatures (all measurements were obtained at room temperature)

\begin{tabular}{|l|l|l|l|l|}
\hline \multirow{2}{*}{ Temperature [K] } & \multicolumn{1}{|c|}{ S74 20414 } & \multicolumn{1}{c|}{ LB-1 $(1 \overline{1} 2)$} & \multicolumn{1}{c|}{ R1 $(00 \overline{1})$} & \multicolumn{1}{c|}{ R1 $(0 \overline{1} 0)$} \\
\cline { 2 - 5 } & \multicolumn{1}{|c|}{ Hardness [GPa] } & \multicolumn{1}{c|}{ Hardness [GPa] } & Hardness [GPa] & Hardness [GPa] \\
\hline pristine (300) & $8.19 \pm 0.12$ & $8.82 \pm 0.46$ & $9.29 \pm 0.16$ & $9.30 \pm 0.30$ \\
\hline 500 & $8.29 \pm 0.09$ & $9.09 \pm 0.51$ & $9.24 \pm 0.17$ & $9.28 \pm 0.27$ \\
\hline 700 & $9.21 \pm 0.13$ & $10.31 \pm 0.71$ & $10.24 \pm 0.15$ & $9.92 \pm 0.26$ \\
\hline 800 & $9.81 \pm 0.17$ & $10.07 \pm 0.39$ & $10.86 \pm 0.34$ & $10.80 \pm 0.35$ \\
\hline 900 & $9.91 \pm 0.18$ & $11.37 \pm 0.78$ & $11.27 \pm 0.38$ & $10.79 \pm 0.27$ \\
\hline 1000 & $10.17 \pm 0.32$ & $12.02 \pm 0.85$ & $10.78 \pm 0.36$ & $10.83 \pm 0.27$ \\
\hline
\end{tabular}

Table 5 Elastic modulus values of allanite-(Ce) samples S74 20414, LB-1, and R1 (two orientations), after annealing at different temperatures (all measurements were obtained at room temperature)

\begin{tabular}{|c|c|c|c|c|}
\hline \multirow[b]{2}{*}{ Temperature [K] } & S74 20414 & LB-1 (11̄2) & $\mathrm{R} 1(00 \overline{1})$ & $\mathrm{R} 1(0 \overline{1} 0)$ \\
\hline & $\begin{array}{c}\text { Elastic Modulus } \\
{[\mathrm{GPa}]}\end{array}$ & $\begin{array}{c}\text { Elastic Modulus } \\
{[\mathrm{GPa}]}\end{array}$ & $\begin{array}{c}\text { Elastic Modulus } \\
{[\mathrm{GPa}]}\end{array}$ & $\begin{array}{c}\text { Elastic Modulus } \\
{[\mathrm{GPa}]}\end{array}$ \\
\hline pristine (300) & $115.3 \pm 2.1$ & $123.2 \pm 5.7$ & $127.0 \pm 1.6$ & $127.2 \pm 3.2$ \\
\hline 500 & $116.0 \pm 2.2$ & $125.0 \pm 5.1$ & $126.5 \pm 1.5$ & $126.1 \pm 2.8$ \\
\hline 700 & $122.4 \pm 1.8$ & $128.9 \pm 6.8$ & $137.1 \pm 2.0$ & $131.1 \pm 2.7$ \\
\hline 800 & $124.0 \pm 1.3$ & $127.1 \pm 4.5$ & $135.3 \pm 3.7$ & $136.0 \pm 3.4$ \\
\hline 900 & $126.3 \pm 1.6$ & $149.6 \pm 9.5$ & $134.2 \pm 4.7$ & $130.9 \pm 3.6$ \\
\hline 1000 & $126.0 \pm 3.9$ & $163.0 \pm 12.0$ & $137.2 \pm 5.8$ & $133.6 \pm 4.9$ \\
\hline
\end{tabular}

\section{Figure Captions}

Fig. 1 Schematic representation of the ideal allanite-(Ce) structure. Data from Dollase (1971), visualized with VESTA software. H atoms have been added after the image of Kartashov et al. (2002). Sites are described in the Introduction.

Fig. 2 Evolution of the integrated intensity [black circles] and FWHM [red boxes] of the (231) Bragg reflex from synchrotron single-crystal X-ray diffraction as a function of annealing temperature from an exemplary grain of sample R1. All measurements were obtained at room temperature. Error bars are within the size of the symbols. The Inset shows the rocking curves before and after annealing at temperatures $573 \mathrm{~K}$ and $673 \mathrm{~K}$. 
Fig. $3{ }^{57}$ Fe Mössbauer spectra of allanite-(Ce) samples a) S74 20414, b) LB-1, and c) R1 after step-wise annealing at the shown temperatures. All measurements were obtained at room temperature. The curves through the measurement points are the result of the fit with six different subspectra (for details see text). The numbering of the peaks is to simplify referencing in the text.

Fig. 4 Powder X-Ray diffractograms for allanite-(Ce) samples a) S74 20414, b) LB-1, and c) R1. The annealing temperatures are shown. All measurements were obtained at room temperature. Highlighted red regions indicate the position of the allanite reflexes. (indices from Čobić et al. (2010)). The signal at $\sim 40-43^{\circ} 2 \theta$ marked with a $(*)$ represents two reflexes with indices $(221)$ and $(\overline{2} 23)$ according to literature. The highlighted blue region marks the position of a calcite reflex in sample S74 20414 (appears at 500-600 K and disappears at $900 \mathrm{~K}$ ).

Fig. 5 High resolution transmission electron microscope (HRTEM) images of preserved crystalline parts in amorphized matrix of radiation-damaged allanite-(Ce) samples a) S74 20414, b) LB-1, and c) R1. Insets show the corresponding FFT analyses.

Fig. 6 Evolution of the a) elastic modulus and b) hardness as a function of annealing temperature of allanite-(Ce)

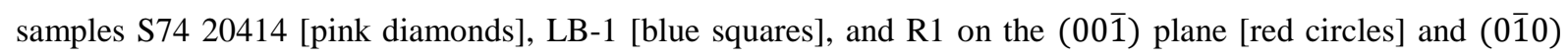
plane [black stars]. All measurements were obtained at room temperature.

Fig. 7 a) Differential scanning calorimetric (DSC) [black] and thermogravimetric (TG) [red] measurements of allanite-(Ce) sample R1 and b) mass spectrometry measurements (masses are assigned to: 12: C, 17: OH, 18: $\mathrm{H}_{2} \mathrm{O}$, and 44: $\mathrm{CO}_{2}$ ).

Fig. 8 a) Differential scanning calorimetric (DSC) [black] and thermogravimetric (TG) [red] measurements of allanite-(Ce) sample LB-1 and b) mass spectrometry measurements (masses are assigned to: 12: C, 17: OH, 18: $\mathrm{H}_{2} \mathrm{O}$, and 44: $\mathrm{CO}_{2}$ ).

Fig. 9 a) Differential scanning calorimetric (DSC) [black] and thermogravimetric (TG) [red] measurements of allanite-(Ce) sample S74 20414 and b) mass spectrometry measurements (masses are assigned to: 12: C, 17: OH, 18: $\mathrm{H}_{2} \mathrm{O}$, and 44: $\mathrm{CO}_{2}$ ).

\section{Figures}

Fig. 1 


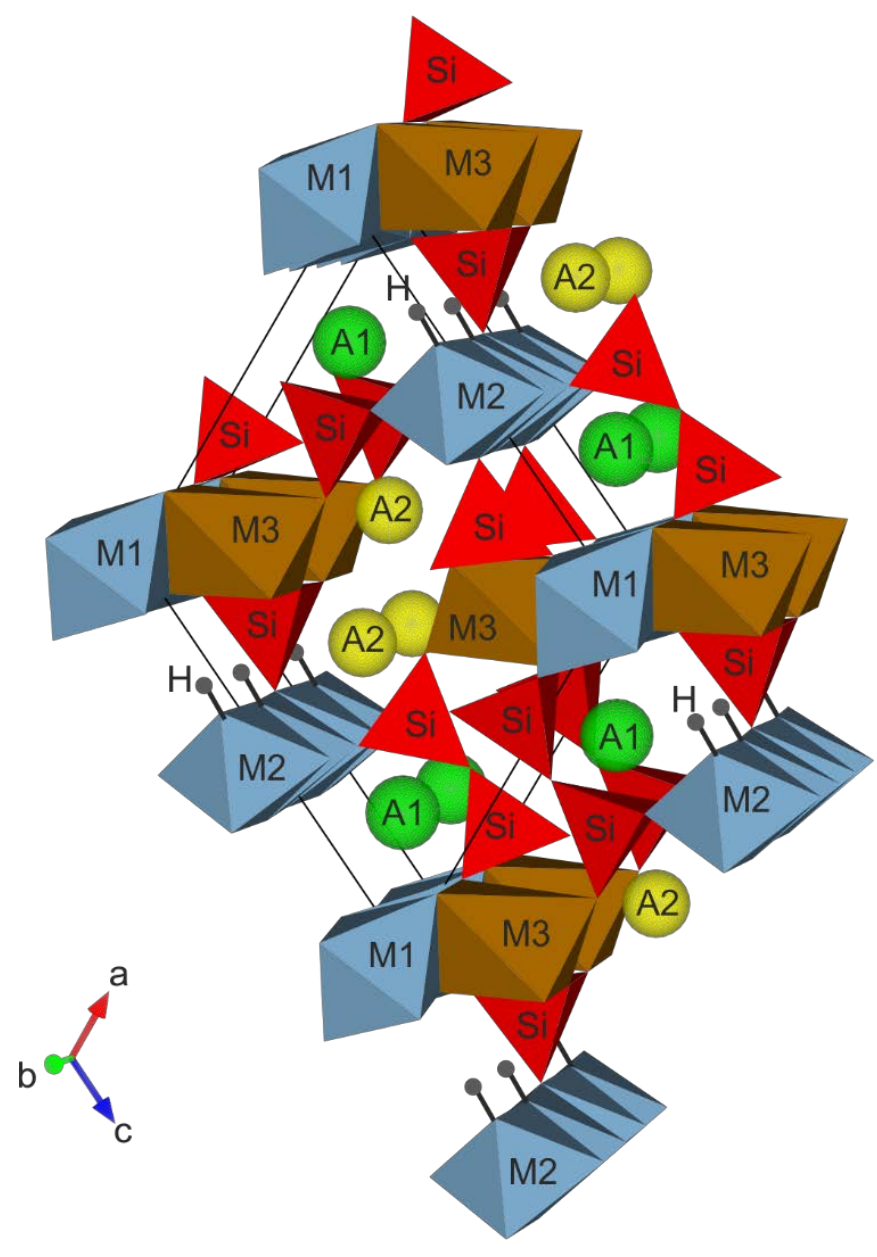

Fig. 2

573

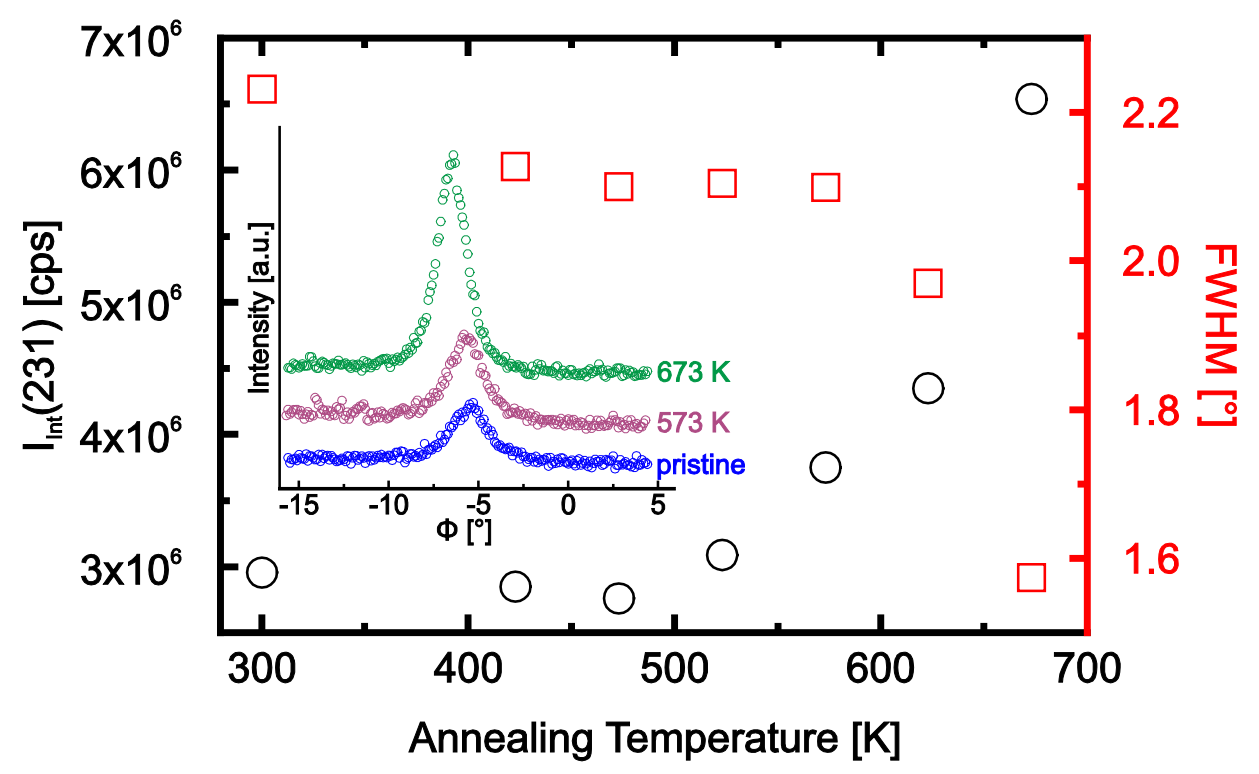

Fig. 3 
a)

b)

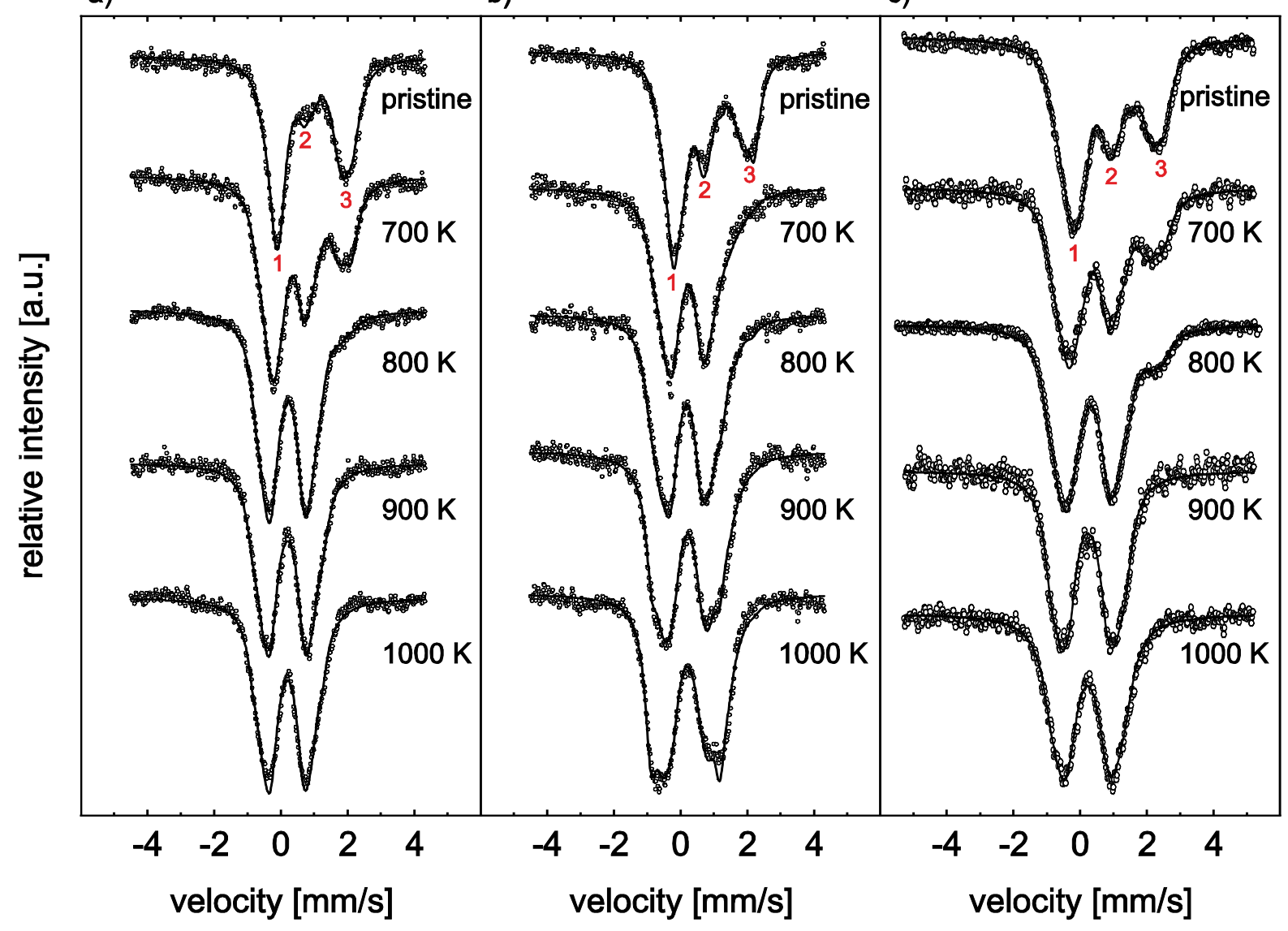

578

579

580

Fig. 4

581 

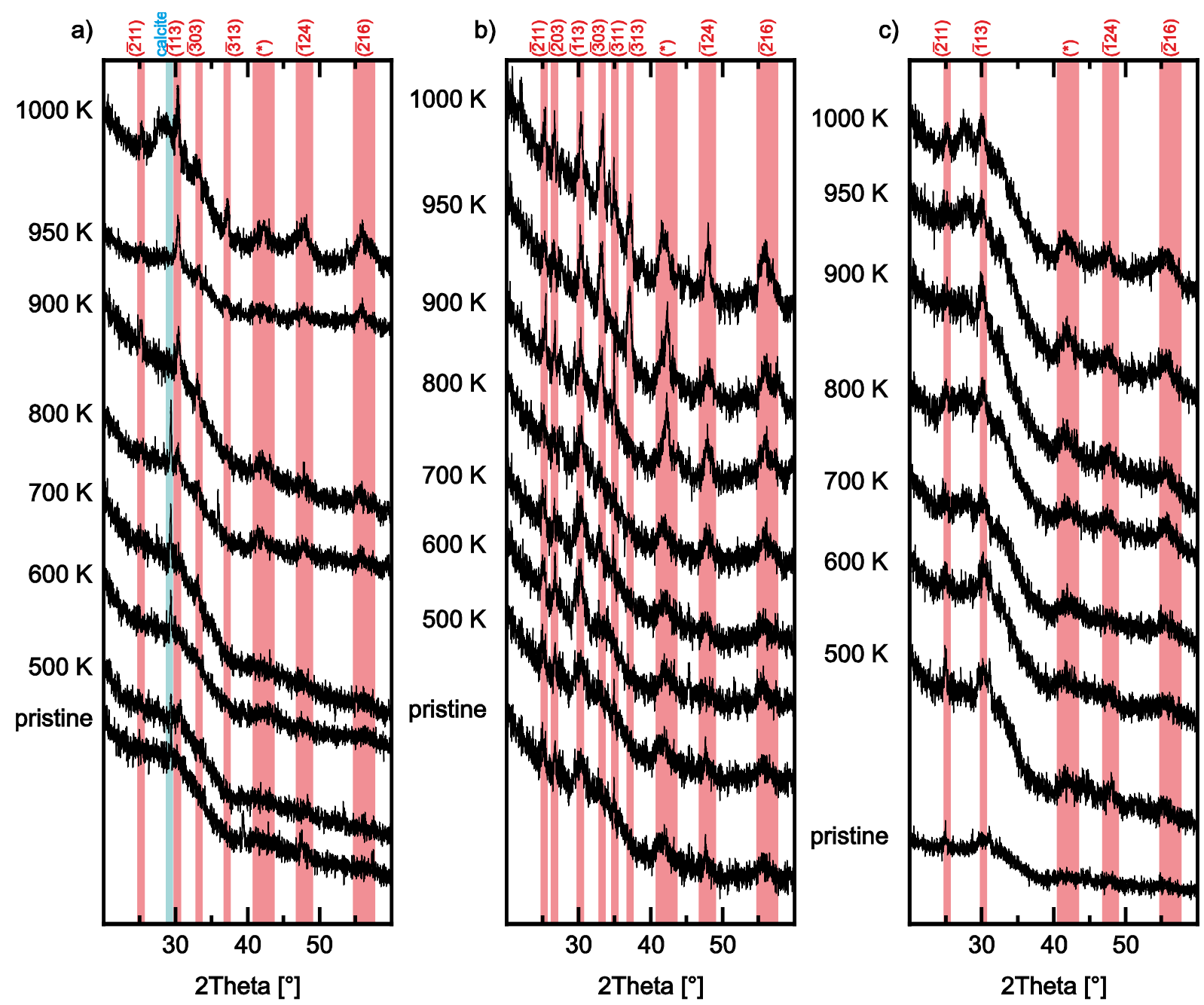

Fig. 5 


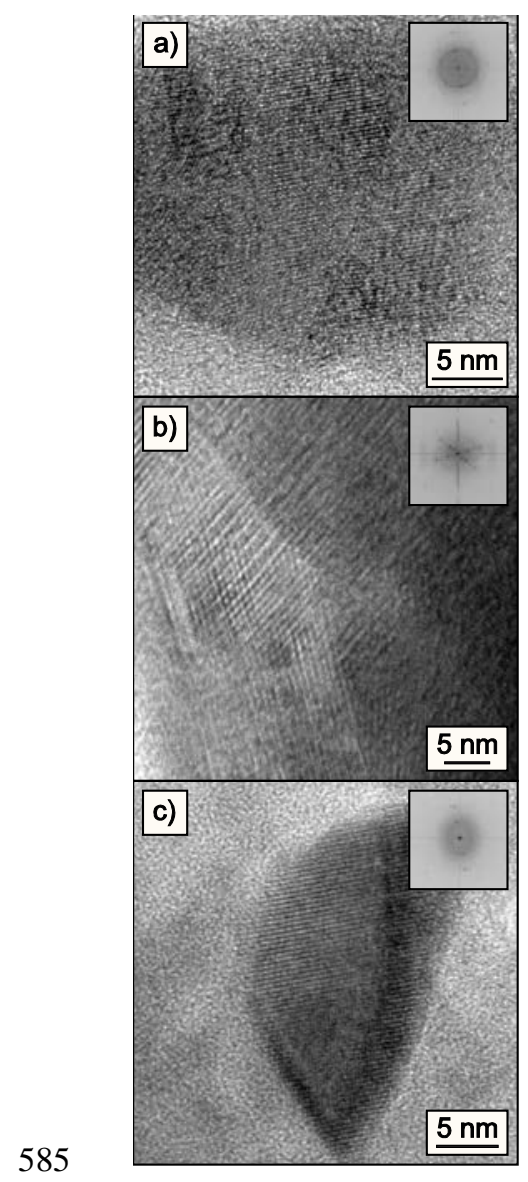

Fig. 6

588

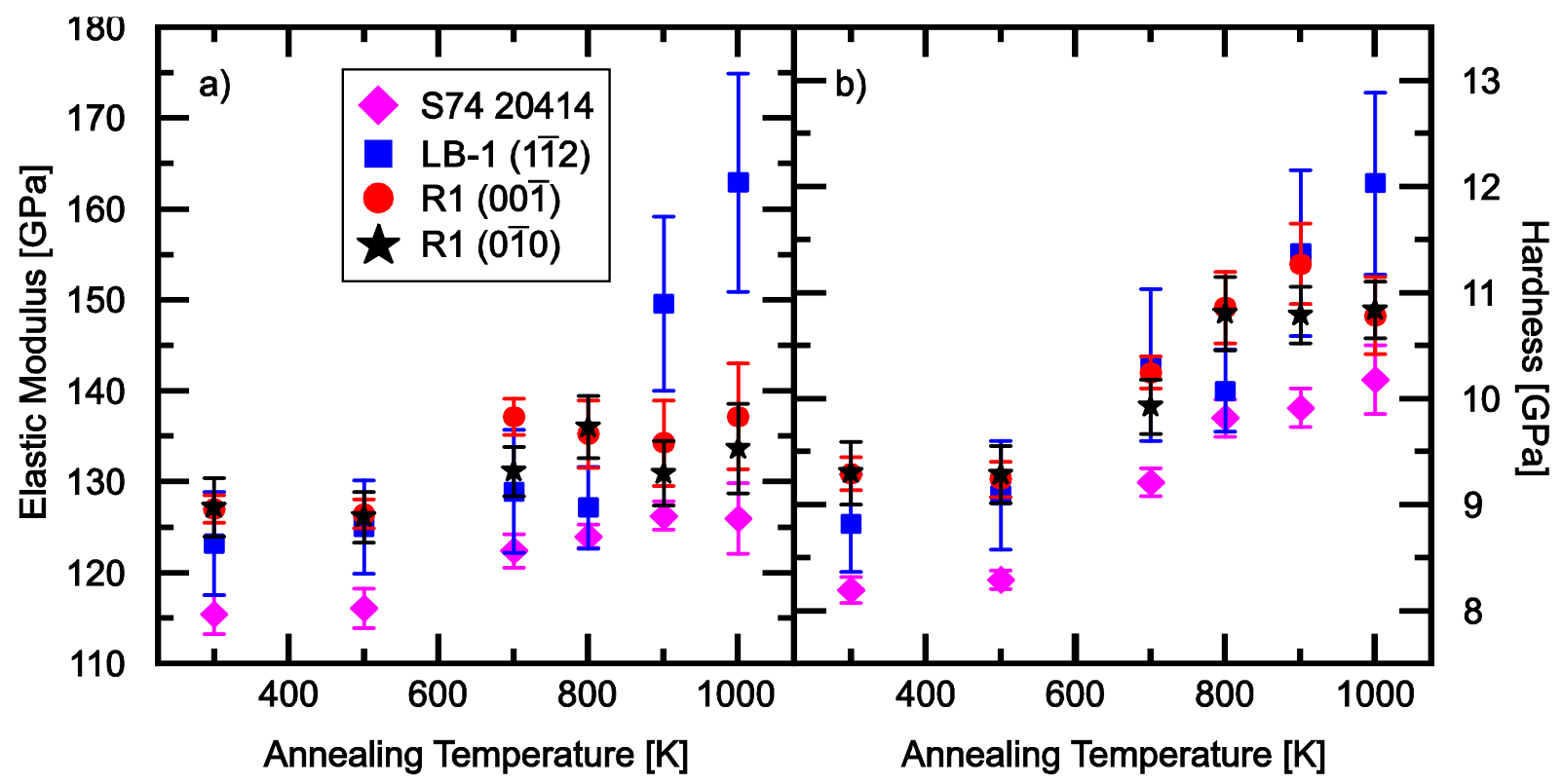

Fig. 7 
a) Temperature [K]

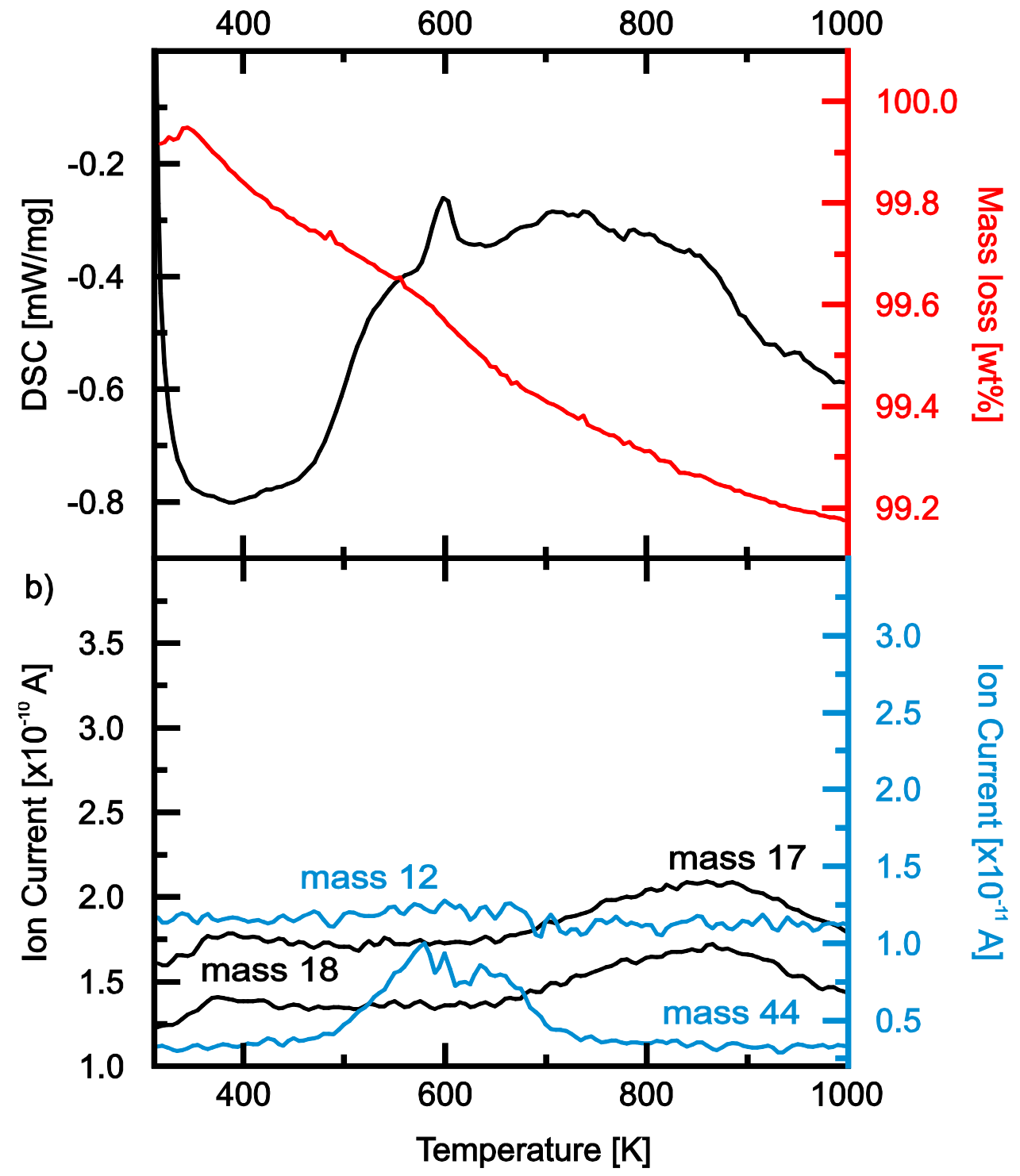


a) Temperature [K]

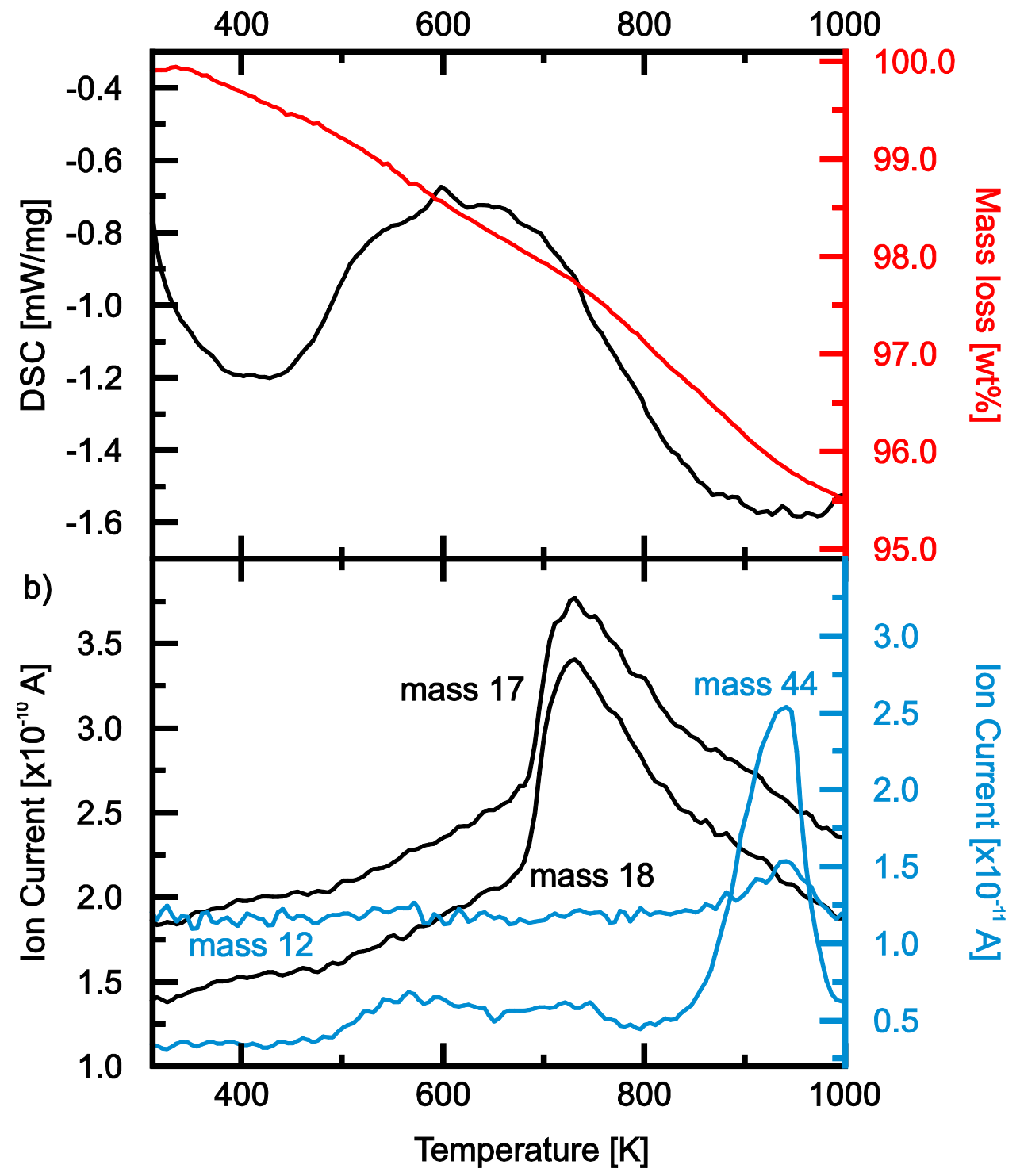


a) Temperature [K]

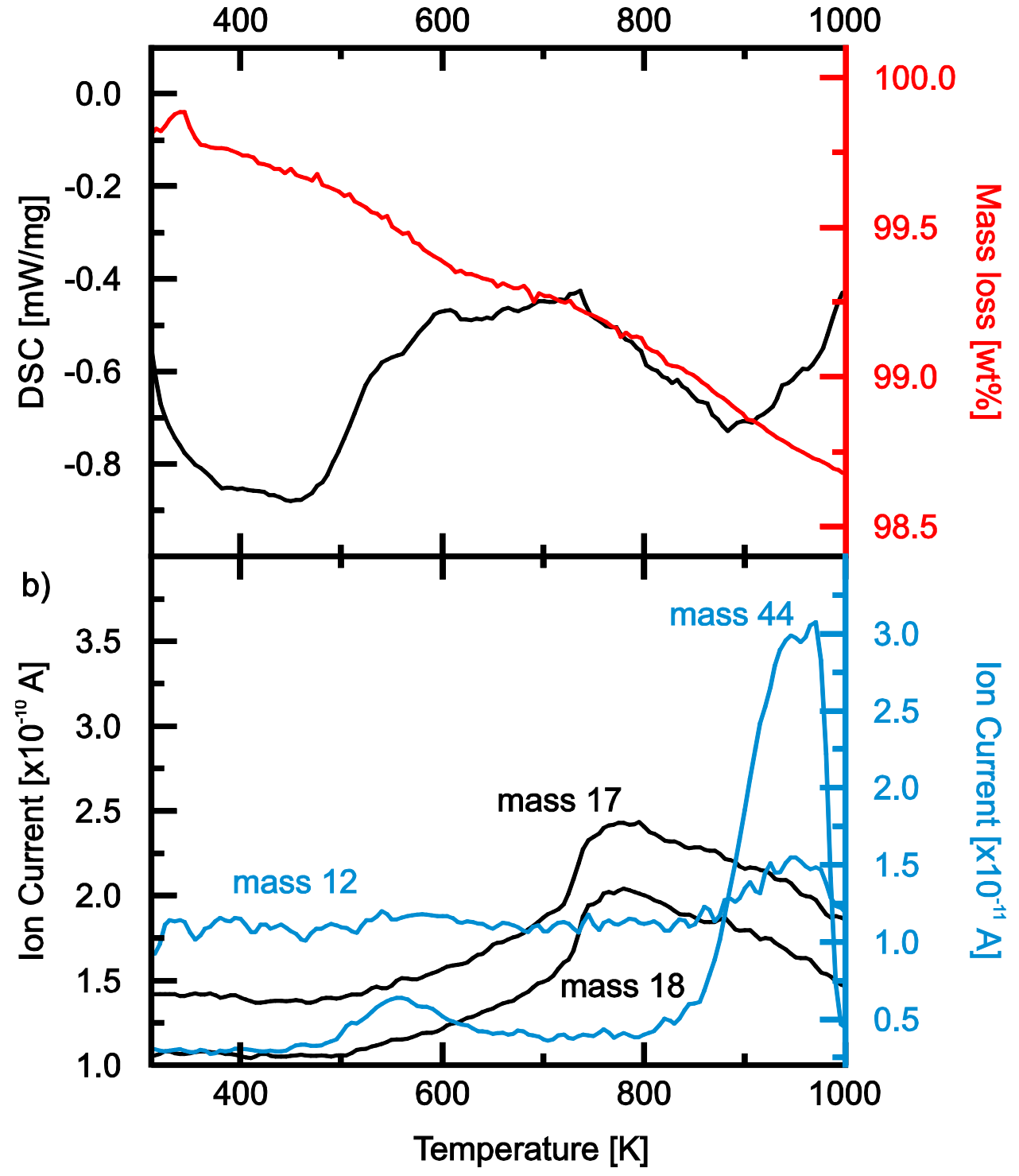

